\title{
BMJ Open Gender and psychosocial factors associated with healthy lifestyle in the Brazilian Longitudinal Study of Adult Health (ELSA-Brasil) cohort: a cross- sectional study
}

\author{
Ana Luísa Patrão, ${ }^{1}$ Maria da Conceição Almeida, ${ }^{2}$ Sheila Maria Alvim Matos, \\ Dora Chor, ${ }^{3}$ Estela M. L. Aquino ${ }^{1}$
}

To cite: Patrão AL,

Almeida MdC, Matos SMA, et al. Gender and psychosocial factors associated with healthy lifestyle in the Brazilian Longitudinal Study of Adult Health (ELSA-Brasil) cohort: a cross-sectional study. BMJ Open 2017;7:e015705. doi:10.1136/ bmjopen-2016-015705

- Prepublication history and additional material for this paper are available online. To view these files please visit the journal online (http://dx.doi. org/10.1136/bmjopen-2016015705).

Received 27 December 2016 Revised 5 June 2017 Accepted 4 July 2017

\section{(a) CrossMark}

${ }^{1}$ Institute of Collective Health, Universidade Federal da Bahia, Salvador, Brazil

${ }^{2}$ FIOCRUZ, Centro de Pesquisas Goncalo Moniz, Salvador, Brazil ${ }^{3}$ FIOCRUZ, Oswaldo Cruz

Foundation, National School of Public Health, Rio de Janeiro, Brazil

Correspondence to Dr Ana Luísa Patrão; lispatrao@gmail.com

\section{ABSTRACT}

Objectives It has been estimated that over $50 \%$ of the premature deaths occurring in Western countries can be attributed to causes rooted in lifestyle. In turn, leading a healthy lifestyle has also been associated with a wide range of psychosocial factors. Today, it is known that these differ among men and women. The present article aimed to identify, from a gender-based perspective, the psychosocial factors associated with healthy lifestyles in the Brazilian Longitudinal Study of Adult Health (ELSABrasil) cohort, the largest study concerning adult health conducted in Latin America to date.

Design This cross-sectional study was conducted using ELSA-Brasil baseline data, collected between 2008 and 2010.

Setting Six Brazilian public higher education and research institutions.

Participants The ELSA-Brasil cohort consists of approximately 15000 employees (8218 women and 6887 men), both currently working and retired.

Main outcome measures The lifestyle indicator was constructed by summing the scores attributed to four different behaviours.

Results The women of the ELSA-Brasil cohort have healthier lifestyles than men. In women, strong associations were found between a healthy lifestyle and age 60 years or older, Asian race and university level of education or higher. In men, being 60 years or older, of Asian or Caucasian race, having a high-school equivalent level of education or higher, being retired, having a housekeeper, having a good or very good self-perception of health and being satisfied with body image were the psychosocial factors associated with leading a healthy lifestyle.

Conclusions The factors that influenced healthy lifestyles were found to differ among men and women, a fact that must be addressed when developing programmes designed to promote health.

\section{INTRODUCTION}

It has been estimated that more than $50 \%$ of the premature deaths in Western countries can be attributed to unhealthy lifestyles and habits
Strengths and limitations of this study

- The large-scale nature of the Brazilian Longitudinal Study of Adult Health (ELSA-Brasil) study conducted in middle-income country on a cohort with a broad age spectrum in the context of a scientific production scenario that has accumulated abundant evidence through the study of adolescents and young or older people.

- Advanced conceptual understanding employed: our study emphasised the role of health promotion instead an usual perspective of disease risk.

- Advanced statistical modelling employed: an indicator of lifestyle was constructed using four components and validated using latent class analysis.

- The ELSA-Brasil cohort is composed of public employees whose participation is strictly voluntary, and, as such, any broad characterisations of these results should, in principle, be interpreted with caution.

- Another relevant limitation is that the variables under study, specifically those that compose the indicator, are purely the result of self-reporting by the participants.

that put health at risk, ${ }^{1-3}$ which can be modified to promote better health. ${ }^{1}$ Four behaviours in particular are considered to place an individual's health at risk: smoking, excessive alcohol consumption, inadequate nutrition and insufficient physical activity. ${ }^{2}{ }^{4-7}$ Despite the prevalence of these unhealthy habits, it is possible for people to modify each of them in an effort to improve overall health. However, there is evidence that individual actions with respect to healthier lifestyles may be limited due to factors that influence an individual's decision-making capacity, such as promotional efforts by the alcohol, tobacco and food industries. ${ }^{8}$ 
Health behaviours and healthy lifestyles are associated with a variety of psychosocial factors. Psychological factors include sociodemographic, familiar and sociocognitive determinants such as professional occupation, education level, age, race/ethnicity, economic status, self-perception body image, self-perceived health status and so on. ${ }^{45-12}$ Professional occupation is considered a factor of influence over an individual's health and lifestyle. ${ }^{10}$ Similarly, voluntary retirement has been shown to be beneficial to health and health behaviours, especially recreational physical activity ${ }^{13} 14$ and moderate alcohol consumption. ${ }^{14}$ Higher education has also been associated with a healthier lifestyle, contributing to a variety of health behaviours, such as performing physical activity, eating a healthy diet, refraining from smoking, limiting alcohol consumption and driving safely, among others. ${ }^{15-17}$

Regarding the influence of sociodemographic factors on lifestyle, studies have demonstrated increasing concern for healthcare with advancing age. ${ }^{18}$ Poverty is one of the major determinants of health. ${ }^{19}$ In addition, race and ethnicity represent some of the best indicators of a population's health status as these are markers of socioeconomic status and social inequality that influence healthy behaviours, as well as access to resources for health protection. ${ }^{20}{ }^{21}$ For instance, a study conducted in North America found that, compared with whites, blacks practice less physical activity and are more obese as a result of inadequate nutrition, indigenous people smoke more and practice less physical activity, and that Latinos practice less physical activity and drink to excess more frequently. ${ }^{20}$ Economic and social capital, as well as the perception of social support, are some of the main social determinants of health and health inequality. ${ }^{22}$ In a literature review, Harvey and Alexander ${ }^{23}$ reported that social support is a strong driver of protective health behaviours, due to opportunities created in terms of individual choices.

Regarding social cognitive factors, an individual's self-perception of body image can influence health behaviours and lifestyle. ${ }^{24}{ }^{25}$ Satisfaction with one's own body seems to be associated with a healthier lifestyle, especially in regard to physical activity and nutrition. ${ }^{24}$ Moreover, the perception of health status has also been identified as fundamental, as a determinant factor of health and with respect to the health-promoting behaviours. ${ }^{26}$

The literature provides abundant evidence regarding the preponderant influence of gender on health ${ }^{27} 28$ and that significant differences exist between men and women. ${ }^{29}$ Yet these differences are frequently naturalised, for instance, by the recurring pronouncement that men smoke more, drink to excess more often and have worse eating habits. ${ }^{128}$ 30-32 To date, relatively few studies have adopted a gender-based perspective when investigating not only lifestyle, ${ }^{33}$ but, above all, the factors that influence it, such as retirement, ${ }^{14}$ the responsibility of caring for children and people with special needs, or the workfamily conflict and its impact on healthy behaviours, as well as health in general. ${ }^{34-36} \mathrm{~A}$ gender perspective is not about sex differences, but analytic looks at the impact of gender (as a social construction) on psychosocial factors that influence health behaviours and lifestyles.

In Brazil, there has been a growing tendency to emphasise health promotion. ${ }^{2}$ In this effort, it is of fundamental importance to identify that factors that hold influence over the health disease process. The Brazilian Longitudinal Study of Adult Health (ELSA-Brasil), the largest study of health in adults ever conducted in Brazil, or even in Latin America, aims to contribute to this body of knowledge. Its main objective is to investigate the incidence of and risk factors (biological, behavioural, environmental, occupational and social) for non-communicable chronic diseases. ${ }^{37}$ Most studies investigating health behaviours use an isolated approach, while those that employ an integrated approach in an attempt to attribute behaviours to different lifestyles are rare, ${ }^{6}$ that is, as in the design of the ELSA-Brasil study (eg, Camelo et al)..$^{38}$ Nonetheless, these have mainly emphasised the role of disease risk instead of health promotion. This study aimed to identify, from a gender-based perspective, the psychosocial factors (sociodemographic, social familial and sociocognitive) associated with leading a healthy lifestyle in the ELSABrasil baseline cohort.

\section{METHOD}

\section{Population study}

The ELSA-Brasil is a cohort study consisting of 15105 public employees (8218 women and 6887 men), both actively working and retired, from six higher education and research institutions in the northeastern, southern and southeastern regions of Brazil: The Federal Universities of Bahia, Espírito Santo, Minas Gerais and Rio Grande do Sul, and the University of São Paulo and the Oswaldo Cruz Foundation. All included individuals were aged between 35 and 74 years at the time of voluntary recruitment (2008-2010). Relevant details pertaining to study methodology have been previously published. ${ }^{37} 39$ Briefly, starting at baseline, the health status of all participants has been followed via annual telephone contact to monitor outcomes of interest, with participants invited to engage in new interviews, as well as resubmit to new measurements and examinations, in-person at regular 3-year intervals.

All cohort members who agreed to participate in the study signed an informed consent form. The ELSA-Brasil study received respective approval from each participating institution's institutional review board.

\section{Measures}

All data presented herein were obtained at baseline via a structured and multidimensional questionnaire ${ }^{40}$ applied by certified trained interviewers. ${ }^{39}$ A series of small pilot studies of increasing complexity were performed to identify and correct potential problems in the data collection instruments and procedures. Central training, 
certification and recertification of interviewers and health professionals responsible for the clinical and laboratory examinations are performed according to the study protocol. ${ }^{37} 40$ The scales/questionnaires were adapted with translation of the original English version into Brazilian Portuguese; retranslation (Portuguese version was translated into English by a second translator) with process and result evaluation; probing; and pretesting. Furthermore, a test-retest reliability study was conducted in a subsample of 261 volunteers to evaluate reproducibility of the Portuguese versions ${ }^{40}$

The variables of interest for this study were as follows:

Outcome variable: An indicator of lifestyle was constructed using the following four components:

1. Current tobacco use, as evaluated by the following question: 'Do you currently smoke cigarettes?' (yes or no).

2. Moderate or excessive alcohol consumption was defined by detailed questions regarding weekly ingestion of alcoholic beverages (red or white wine, beer or spirits), categorised as not excessive (men: $<210 \mathrm{~g}$ /week; women: $<140 \mathrm{~g}$ /week) or excessive (men: $\geq 210 \mathrm{~g} /$ week; women $: \geq 140 \mathrm{~g} /$ week), according to recommendations by Duncan et al. ${ }^{41}$ A typical question format consisted of: 'How many glasses of wine do you consume per week?'

3. Recreational physical activity was measured by the International Physical Activity Questionnaire, ${ }^{42}$ with respondents classified as active $(\geq 150 \mathrm{~min} /$ week of walking or other moderate activity, or $\geq 60 \mathrm{~min} /$ week of intense physical activity) or inactive $(<150 \mathrm{~min} /$ week of walking or other moderate activity, or $<60 \mathrm{~min} /$ week of intense physical activity). Moderate activity encompassed swimming or riding a bike at a moderate pace, practising recreational sports and so on. Intense activity was considered as running, exercising at a gym, fast-paced cycling, practising competitive sports and so on. A typical question format was: 'How many days a week do you go for a walk in your free time?'

4. Proper nutrition was evaluated via participant reporting on daily consumption of vegetables, greens and fruits, at least once a day, via two questions: (1) 'How often do you usually eat raw, cooked or braised vegetables, not including potatoes, cassava/manioc root or yams?' and (2) 'How often do you usually eat fruits, not including drinking fruit juice?'

The indicator of lifestyle was constructed by summing the scores attributed to these four different behaviours (five questions, because nutrition behaviour has two questions), ranging from 0 (absence of any healthy behaviours) to 5 (presence of all healthy behaviours). This indicator was subsequently dichotomised (ie, a more or less healthy lifestyle) and validated using latent class analysis (LCA) ${ }^{43}$ to classify individuals into homogeneous subgroups. According to LCA, the probability that the individuals in the ELSA-Brasil cohort would be distributed into two classes was high (there are two types of health behaviour
Table 1 Parameters estimated for the model with two latent classes

\begin{tabular}{llc}
\hline Indicators & $\begin{array}{l}\text { Less healthy } \\
\text { (class I) (\%) }\end{array}$ & $\begin{array}{l}\text { Healthier } \\
\text { (class II) (\%) }\end{array}$ \\
\hline $\begin{array}{l}\text { Marginal probability } \\
\text { Entropy }\end{array}$ & 87.4 & 98.4 \\
$\begin{array}{l}\text { Conditional probability } \\
\quad \text { Does not smoke }\end{array}$ & 82.7 & 91.1 \\
$\begin{array}{l}\text { Does not drink } \\
\text { Eats vegetables and greens } \\
\text { daily }\end{array}$ & 24.4 & 94.9 \\
\hline $\begin{array}{l}\text { Eats fruit daily } \\
\text { Performs physical activity }\end{array}$ & 29.9 & 79.1 \\
\hline
\end{tabular}

patterns; entropy $=0.75$ ). When the results of the lifestyle indicator were compared with the result of the LCA, agreement was $83.2 \%$, with a Kappa coefficient of 0.65 . Table 1 shows the values for each behaviour regarding the LCA results.

Psychosocial variables (possible predictors): Sociodemographic and family variables (age, race/skin colour, education level, professional status, family composition, monthly housekeeping service). Information obtained via questionnaire.

Self-perception of health status: Participants were asked, "In general, compared to others your age, how do you consider your state of health?" (very good, good, fair, poor or very poor).

Body image satisfaction: Data obtained by applying a silhouetted scale with respect to two questions: 'Which image best represents your body shape today?' and 'Which image best represents the body shape you would like to have?' Responses were recorded according to each participant's choice of one of 15 cards depicting silhouettes presented individually, arranged in ascending order with a progressive variation along a scale ranging from very thin to heavyset, corresponding to a mean body mass index varying between 17.5 and $47.5 \mathrm{~kg} / \mathrm{m}^{2}{ }^{44}$

\section{Analysis}

Statistical analyses were carried out separately by sex to highlight gender differences. Frequency distributions of independent variables were calculated in accordance with lifestyle and sex indicators. The covariates that were found to be associated with lifestyle under bivariate analysis using Pearson's $\chi^{2}$ test ( $5 \%$ significance level) were selected for logistic regression analysis. These covariates were submitted to tetrachoric correlation analysis to avoid the inclusion of any with a correlation coefficient (rho) above 0.60 in the model. According to the research objectives, an explorative model of analysis was used. The selection of variables in the model occurred through a forward strategy. At each step, a goodness-of-fit test was made to evaluate the contribution of each variables and also to understand if the selected variables would be adequate for men and women models. The final model 


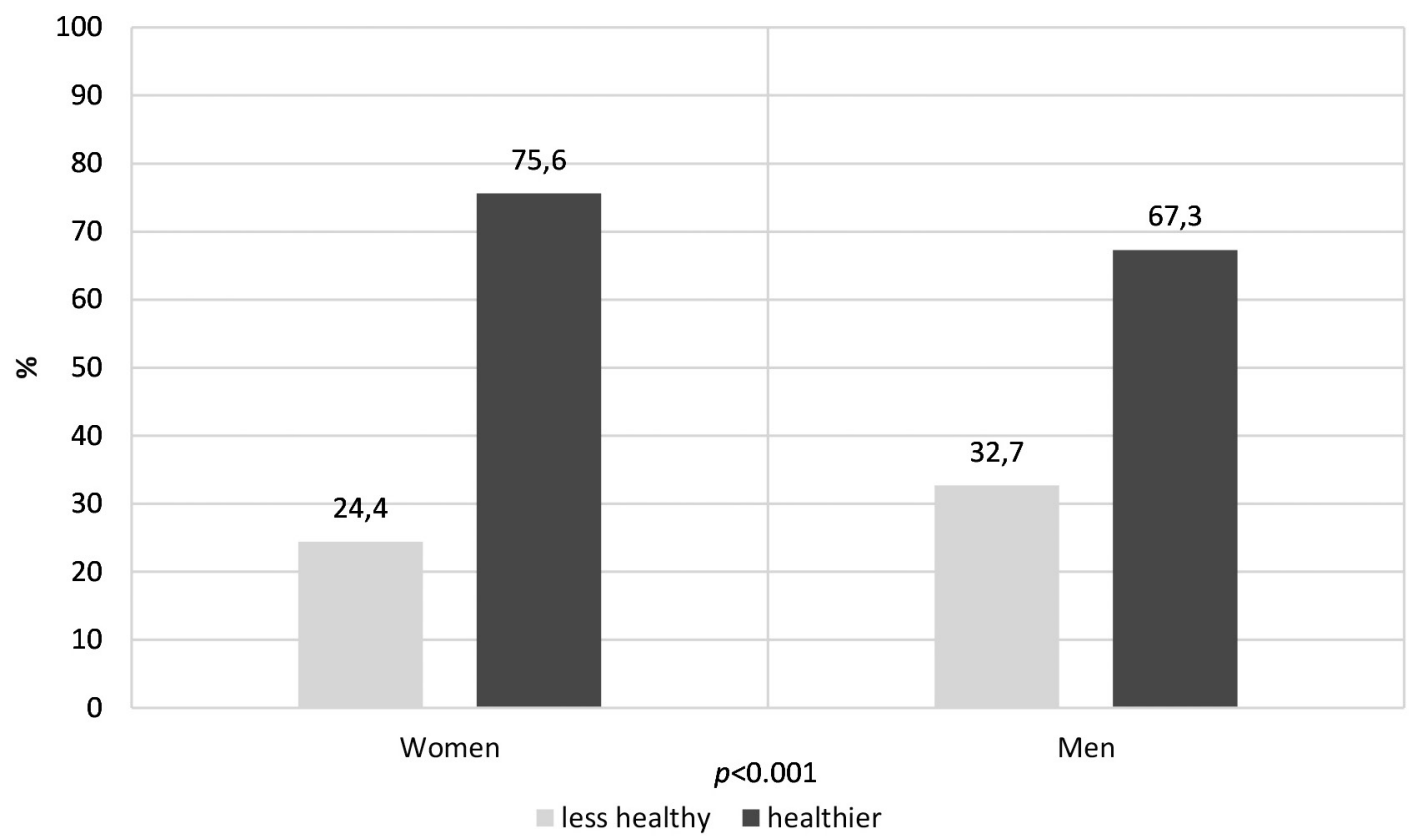

Figure 1 Distribution of study participants according to lifestyle and sex.

was evaluated using a goodness-of-fit test, as well as by calculating the area under the receiver operating characteristic (ROC) curve, and was the one that presented the best adjustment. The regression was made between lifestyles and psychosocial variables that are correlated with the outcome variable. These psychosocial variables were selected in accordance with the literature indicate that they are associated with lifestyles. All analyses were conducted using STATA V. 13 statistical software.

\section{RESULTS}

Approximately $75 \%$ of the women and $67 \%$ of the men studied were classified as having a healthy lifestyle, with statistical significance observed $(\mathrm{p}<0.001)$ (figure 1$)$.

Among women and men, those 60 years and older had the healthiest lifestyles $(84.8 \%$ and $75.7 \%$, respectively), with consistently higher proportions seen in women of all age groups (table 2). Regarding race/skin colour, those who self-reported being white/Caucasian or, particularly, those of Asian origin were considered to lead healthier lifestyles. Blacks, mixed-race (brown-skinned or mixed colour) and indigenous individuals were at a greater disadvantage in terms of healthy behaviours, regardless of sex. A clear relationship was observed between education level and lifestyle, that is, a higher level of schooling corresponded to a greater proportion of healthy lifestyle in both women and men. Retirement also seemed to allow women $(83.9 \%)$ and men $(76.1 \%)$ to engage in healthier lifestyles.

With respect to social-familial variables, it was observed that, regardless of sex, participants led healthier lifestyles when they did not live with children or lived at home with children over 14 years of age, as well as when they had housekeeping services on a monthly basis.
Regarding sociocognitive variables, both women and men who perceived their health as 'good' or 'very good' led healthier lifestyles, in addition to those who were satisfied with body image.

When the variables were analysed simultaneously among women, the following factors remained associated with a healthier lifestyle: an age of $50-59$ years $(\mathrm{OR}=1.41$; IC $95 \% 1.24$ to 1.61$)$; age 60 years or older $(\mathrm{OR}=2.21$; IC $95 \% 1.79$ to 2.72$)$; race/skin colour Asian $(\mathrm{OR}=2.29$; IC $95 \% 1.57$ to 3.36$)$, white/Caucasian ( $\mathrm{OR}=1.57$; IC $95 \% 1.36$ to 1.81$)$ or mixed race (OR=1.24; IC 95\% 1.07 to 1.44); a high-school equivalent (secondary) level of education ( $\mathrm{OR}=1.31$; IC $95 \% 1.09$ to 1.57 ) or university degree (tertiary) (OR=1.89; IC 95\% 1.55 to 2.29); being retired ( $\mathrm{OR}=1.33$; IC $95 \% 1.12$ to 1.59$)$; the self-perception of health status as good/very good $(\mathrm{OR}=1.27$; IC $95 \% 1.12$ to 1.45 ) (table 3).

Among men, simultaneous analysis revealed that a healthy lifestyle continued to be associated with age 60 years or older ( $\mathrm{OR}=1.32$; IC $95 \% 1.08$ to 1.61 ); white/ Caucasian race/skin colour (OR=1.20; IC 95\% 1.02 to 1.41 ) or Asian (OR=1.66; IC 95\% 1.05 to 2.60); a high-school equivalent (secondary) level of education $(\mathrm{OR}=2.16$; IC $95 \% 1.83$ to 2.54$)$ or university (tertiary) level $(\mathrm{OR}=1.36$; IC $95 \% 1.17$ to 1.59$)$; being retired $(\mathrm{OR}=1.31$; IC $95 \% 1.07$ to 1.61$)$. The social-familial variable of having a housekeeper ( $\mathrm{OR}=1.34$; IC 95\% 1.16 to 1.56$)$, the sociocognitive variable of self-perception of health status as good or very good $(\mathrm{OR}=1.20$; IC $95 \% 1.02$ to 1.41$)$ and being satisfied with body image (OR=1.23; IC 95\% 1.07 to 1.41) were all found to present statistical significance. In contrast to what was seen in women with respect to the latter factor, these variables maintained significance even after adjustment 
Table 2 Distribution of lifestyle among men and women of the Brazilian Longitudinal Study of Adult Health (ELSA-Brasil) study cohort, according to selected psychosocial characteristics - baseline study: 2008-2010

\begin{tabular}{|c|c|c|c|c|c|c|}
\hline \multirow[b]{4}{*}{ Psychosocial characteristics selected } & \multirow[b]{4}{*}{$\mathrm{n}$} & \multicolumn{2}{|c|}{ Women } & & \multirow{2}{*}{\multicolumn{2}{|c|}{$\begin{array}{c}\text { Men } \\
\text { Lifestyle }\end{array}$}} \\
\hline & & \multicolumn{2}{|c|}{ Lifestyle } & & & \\
\hline & & $\begin{array}{l}\text { Less } \\
\text { healthy }\end{array}$ & $\begin{array}{l}\text { More } \\
\text { healthy }\end{array}$ & & $\begin{array}{l}\text { Less } \\
\text { healthy }\end{array}$ & $\begin{array}{l}\text { More } \\
\text { healthy }\end{array}$ \\
\hline & & $\%$ & $\%$ & $\mathbf{n}$ & $\%$ & $\%$ \\
\hline \multicolumn{7}{|l|}{ Sociodemographic } \\
\hline \multicolumn{7}{|l|}{ Age range } \\
\hline $35-49$ years & 3403 & 29.8 & 70.2 & 2912 & 34.6 & 65.4 \\
\hline 50-59years & 2956 & 23.6 & 76.4 & 2350 & 35.8 & 64.2 \\
\hline 60 or + years & 1707 & 15.2 & 84.8 & 1512 & 24.3 & 75.7 \\
\hline \multicolumn{7}{|l|}{ Race/skin colour } \\
\hline Black & 1441 & 33.4 & 66.6 & 932 & 39.2 & 60.8 \\
\hline Mixed race & 2140 & 27.3 & 72.7 & 1998 & 39.2 & 60.8 \\
\hline White/Caucasian & 4108 & 20.4 & 79.6 & 3535 & 27.7 & 72.3 \\
\hline Asian & 238 & 14.7 & 85.3 & 126 & 22.2 & 77.8 \\
\hline Indigenous & 64 & 28.2 & 71.8 & 91 & 40.7 & 59.3 \\
\hline \multicolumn{7}{|l|}{ Education level } \\
\hline Basic education level (primary) & 765 & 31.24 & 68.76 & 1128 & 45.66 & 54.34 \\
\hline High-school equivalent (secondary) & 2908 & 29.61 & 70.39 & 2215 & 39.14 & 60.86 \\
\hline University degree or higher (tertiary) & 4393 & 19.83 & 80.17 & 3431 & 24.28 & 75.72 \\
\hline \multicolumn{7}{|l|}{ Professional status } \\
\hline Currently working & 6196 & 26.9 & 73.1 & 5679 & 34.4 & 65.6 \\
\hline Retired & 1870 & 16.1 & 83.9 & 1095 & 23.9 & 76.1 \\
\hline \multicolumn{7}{|l|}{ Social-familial } \\
\hline \multicolumn{7}{|l|}{ Age of children in household } \\
\hline Up to 14 years of age & 1660 & 28.5 & 71.5 & 1870 & 35.1 & 64.9 \\
\hline Age 14 or older, or no children at home & 6406 & 23.4 & 76.6 & 4904 & 31.8 & 68.2 \\
\hline \multicolumn{7}{|l|}{ Monthly housekeeper } \\
\hline Yes & 5980 & 26.3 & 73.7 & 5159 & 35.9 & 64.1 \\
\hline No & 2086 & 19.2 & 80.8 & 1614 & 22.4 & 77.6 \\
\hline \multicolumn{7}{|l|}{ Sociocognitive } \\
\hline \multicolumn{7}{|l|}{ Self-perceived health status } \\
\hline Very poor/poor/fair & 1609 & 29.9 & 70.1 & 1355 & 40.0 & 60.0 \\
\hline Good/very good & 6457 & 23.1 & 76.9 & 5419 & 30.9 & 69.1 \\
\hline \multicolumn{7}{|l|}{ Body image satisfaction } \\
\hline Yes & 878 & 21.4 & 78.6 & 1284 & 29.8 & 70.2 \\
\hline No & 7133 & 24.8 & 75.2 & 7439 & 33.5 & 66.5 \\
\hline
\end{tabular}

IC $95 \%=\mathrm{Cl}$ of $95 \%$ (source: ELSA-Brasil).

by logistical regression. A more detailed analysis of associations among the healthier habits of men who had a housekeeper on a monthly basis revealed that those who availed themselves of this service ate more vegetables and fruits and performed more physical activity (data not shown).

\section{DISCUSSION}

This study was able to show that, among women, an older age (60 years or more), Asian race and a university or higher level of education were the factors most strongly associated with a healthy lifestyle. Equally significantly associated with a healthier lifestyle, although to a lesser extent, were the psychosocial factors Caucasian/white 
Table 3 Psychosocial factors associated with a healthy lifestyle among women and men-Brazilian Longitudinal Study of Adult Health (ELSA-Brasil) baseline study: 2008-2010

\begin{tabular}{|c|c|c|c|c|}
\hline \multirow[b]{3}{*}{ Factors } & \multicolumn{2}{|c|}{ Women } & \multicolumn{2}{|c|}{ Men } \\
\hline & \multirow[b]{2}{*}{ Unadjusted } & Adjusted & \multirow[b]{2}{*}{ Unadjusted } & \multirow{2}{*}{$\begin{array}{c}\text { Adjusted } \\
\text { OR (IC 95\%) }\end{array}$} \\
\hline & & OR (IC 95\%) & & \\
\hline \multicolumn{5}{|l|}{ Sociodemographic } \\
\hline \multicolumn{5}{|l|}{ Age range } \\
\hline $35-49$ & 1.00 & 1.00 & 1.00 & 1.00 \\
\hline $50-59$ & $1.37(1.22-1.53)$ & $1.41(1.24$ to 1.61$)$ & $0.95(0.85-1.06)$ & 0.99 (0.87 to 1.20$)$ \\
\hline $60+$ & $2.37(2.03-2.76)$ & 2.21 (1.79 to 2.72 ) & $1.65(1.43-1.90)$ & $1.32(1.08$ to 1.61$)$ \\
\hline \multicolumn{5}{|l|}{ Race/skin colour } \\
\hline Black & 1.00 & 1.00 & 1.00 & 1.00 \\
\hline Mixed race & $1.33(1.15-1.54)$ & 1.24 (1.07 to 1.44$)$ & $0.99(0.85-1.17)$ & 0.91 (0.77 to 1.07$)$ \\
\hline White/Caucasian & $1.95(1.71-2.23)$ & $1.57(1.36$ to 1.81$)$ & $1.77(1.44-1.95)$ & $1.20(1.02$ to 1.41$)$ \\
\hline Asian & $2.90(1.99-4.22)$ & 2.29 (1.57 to 3.36$)$ & $2.25(1.45-3.49)$ & 1.66 (1.05 to 2.60$)$ \\
\hline Indigenous & $1.28(0.73-2.23)$ & 1.22 (0.69 to 2.14$)$ & $0.93(0.61-1.45)$ & 0.97 (0.62 to 1.53$)$ \\
\hline \multicolumn{5}{|l|}{ Education level } \\
\hline Basic education level (primary) & 1.00 & 1.00 & 1.00 & 1.00 \\
\hline $\begin{array}{l}\text { High-school equivalent } \\
\text { (secondary) }\end{array}$ & $1.08(0.90-1.28)$ & 1.31 (1.09 to 1.57$)$ & $1.30(1.12-1.50)$ & 2.16 (1.83 to 2.54$)$ \\
\hline $\begin{array}{l}\text { University degree or higher } \\
\text { (tertiary) }\end{array}$ & $1.83(1.55-2.17)$ & 1.89 (1.55 to 2.29$)$ & $2.62(2.27-3.01)$ & $1.36(1.17$ to 1.59$)$ \\
\hline \multicolumn{5}{|l|}{ Professional status } \\
\hline Currently working & 1.00 & 1.00 & 1.00 & 1.00 \\
\hline Retired & $1.92(1.67-2.20)$ & 1.33 (1.12 to 1.59$)$ & $1.66(1.43-1.93)$ & $1.31(1.07$ to 1.61$)$ \\
\hline \multicolumn{5}{|l|}{ Social-familial } \\
\hline \multicolumn{5}{|l|}{ Children $<14$ years living at home } \\
\hline Yes & 1.00 & 1.00 & 1.00 & 1.00 \\
\hline No & $1.30(1.15-1.47)$ & $0.98(0.85$ to 1.13$)$ & $1.16(1.03-1.30)$ & $1.10(0.97$ to 1.24$)$ \\
\hline \multicolumn{5}{|l|}{ Monthly housekeeper } \\
\hline No & 1.00 & 1.00 & 1.00 & 1.00 \\
\hline Yes & $1.49(1.32-1.69)$ & 1.13 (0.98 to 1.29$)$ & $1.94(1.70-2.21)$ & 1.34 (1.16 to 1.56$)$ \\
\hline \multicolumn{5}{|l|}{ Sociocognitive } \\
\hline \multicolumn{5}{|l|}{ Self-perceived health status } \\
\hline Very poor/poor/fair & 1.00 & 1.00 & 1.00 & 1.00 \\
\hline Good/very good & $1.42(1.25-1.60)$ & $1.27(1.12$ to 1.45$)$ & $1.49(1.31-1.68)$ & 1.24 (1.09 to 1.42$)$ \\
\hline \multicolumn{5}{|l|}{ Body image satisfaction } \\
\hline No & 1.00 & 1.00 & 1.00 & 1.00 \\
\hline Yes & $1.21(1.02-1.43)$ & 1.16 (0.97 to 1.38$)$ & $1.18(1.04-1.35)$ & $1.23(1.07$ to 1.41$)$ \\
\hline
\end{tabular}

IC $95 \%=\mathrm{Cl}$ of $95 \%$ (source: ELSA- Brasil.

race/skin colour, retirement status and a positive perception of health status. For men, the psychosocial factors associated with a healthier lifestyle were as follows: age 60 years or older, Caucasian or Asian race, high school (secondary) or higher (tertiary) level of education, retirement status, having a housekeeper, having a good or very good perception of health status and being satisfied with body image. The differences between men and women are not strikingly large. However, the study and discussion focuses on differences, because the objective is to evaluate the importance of gender, as a social and analytical variable, in the psychosocial variables that influence lifestyles.

The present results serve to confirm the consensus in the scientific literature ${ }^{13132}$ with respect to the greater pursuit of healthier lifestyles by women, regardless of social class. By including social-familial and sociocognitive factors, described in the literature as markers of gender roles, we were able to verify that the selected variables, 
contrary to our expectation, held greater influence over of healthier behaviours among men. An example of this was having monthly housekeeping services, which no studies have previously attempted to directly investigate, an exception being women who are benefited by support in the performance of household duties. One possible interpretation could be that, in a society with marked gender inequality, accentuated by the tradition of slavery, in which men are dependent on women to perform household tasks, these duties, especially the preparation of meals, are performed by female workers when other family members are absent. This finding provided motivation for a more detailed examination of this subgroup, which subsequently confirmed that men who had regular housekeeping services ate more vegetables and fruits and performed more physical activity (perhaps due to greater time availability as a result of assistance with household tasks). From this perspective, these results are consistent with what has been purported by other studies, which consider social support to be a strong driver of health behaviours. $^{23}$

Age was shown to be a relevant factor in our analysis, that is, older participants of both sexes tended to have healthier lifestyles. It is important to note that, specifically in women, the tendency to lead a healthier lifestyle with advancing age had an earlier onset, beginning at 50 years of age. A previous study by Green $e t a t^{5}$ also found a positive effect with respect to age, particularly in women, with regard to level of alcohol consumption. Deeks et $a l^{18}$ reached similar conclusions in a study involving an Australian adult population, reporting that individuals of greater age exhibited healthier behaviours.

Race/skin colour was also found to be a factor associated with lifestyle, both in women and men. Above all, whites and individuals of Asian origin had the healthiest lifestyles of the ELSA-Brasil cohort. It is possible that, in addition to cultural aspects (especially among those of Asian origin), socioeconomic conditions may be the explanation for this phenomenon. As a rule, in Brazil, whites/Caucasians and Asians are among the strata with higher incomes and social status, while blacks, mixed race and indigenous people generally group within less-privileged social strata. ${ }^{46}$ It is known that these racial and ethnic inequalities are related to, above all, income constraints, lower levels of education, increased daily stress and reduced access to social opportunities and resources, which may hinder the adoption of a healthier lifestyle. ${ }^{20} 21$

Education level is another factor associated with a healthy lifestyle, both in men and women. This fact is in line with the scientific literature, as evidenced by several studies conducted in diverse cultures, including Hungarian, ${ }^{17}$ Chinese $^{16}$ and British ${ }^{15}$ societies, all of which reported similar results. Higher education levels correlate with an increased tendency to lead a healthy lifestyle. Higher levels of education have been associated with a number of factors that favour healthy behaviours related to lifestyle, such as having health insurance, higher income level and, above all, the cognitive capacity required for an in-depth understanding of information on health. ${ }^{15}$

With respect to professional status, being retired was associated with leading a healthier lifestyle in both the women and men studied by ELSA-Brasil. A previous study conducted by Midanik $e t a l^{13}$ also found that retired individuals, regardless of gender, experience lower levels of stress, and also practice higher levels of physical activity. Specifically, in women, levels of alcohol consumption were lower in retirement as opposed to when actively working. A review by Zantinge $e t \mathrm{al}^{14}$ also found benefits in terms of health behaviours arising from retirement, namely with regard to recreational physical activity and alcohol consumption (when voluntarily retired). In ELSA-Brasil, this association was observed with respect to practising recreational physical activity. ${ }^{36}$ The results of this study confirm that retirement status and age independently lead to improvements in lifestyle. Possibly, advancing age induces a greater awareness of the importance of promoting health and preventing disease for those who want to be active and healthy as they grow older. Retirement, in turn, allows for more time to be dedicated to this effect (eg, the preparation of healthy meals and practising physical activity).

Regarding sociocognitive factors, having a good or very good perception of health status was found to be associated with leading a healthy lifestyle. This has also been identified in other studies focused on healthy behaviours among adults in Brazil, ${ }^{47}$ as well as in Portugal. $^{26}$

Surprisingly, body image perception was associated with a healthier lifestyle exclusively among men. Previous studies investigating the contrary effects arising from dissatisfaction with body image found that this was associated with binge eating and other eating disorders, in addition to other insalubrious behaviours, such as low levels of physical activity among both sexes, as well as smoking in men. ${ }^{48}$ The present results serve to contribute to the scientific debate surrounding the relationship between body image and lifestyle by evaluating the beneficial effects of being satisfied with one's own body image. Additional investigation and a deeper analysis in the context of ELSA-Brasil could better elucidate this association, since the scientific literature has emphasised the great importance that body image holds for women, especially in Western cultures. ${ }^{49}$

This study is limited by some relevant aspects. First, the ELSA-Brasil cohort is composed of public employees whose participation is strictly voluntary, and, as such, any broad characterisations of these results should, in principle, be interpreted with caution. However, similarities were seen herein with respect to the prevalence of health behaviours and their distribution compared with representative data reported by a national telephone survey conducted periodically on adults living in Brazil's 27 state capitals and the Federal District. ${ }^{39}$ Moreover, our interest here was to investigate healthy lifestyles by more 
vulnerable subgroups in order to identify and prioritise actions designed to promote health.

Since the dataset herein was cross-sectional in nature, that is, obtained from the ELSA-Brasil survey baseline, it was not possible to infer a temporal sequence of events, for example, the relationship between leading a healthy lifestyle and self-perception of health or satisfaction with body image. However, the use of a prospective study design would make it possible to confirm these findings through the future analysis of longitudinal data, allowing researchers to more precisely identify psychosocial predictors.

Another relevant limitation is that the variables under study, specifically those that compose the indicator, are purely the result of self-reporting by the participants. Future studies would benefit from the use of more objective markers (eg, the level of physical activity practised). Nonetheless, in the context of Brazil this survey is still innovative as it is based on data from a large sample of public servants. Furthermore, researchers are intending to begin to measure physical activity through the use of an actigraph during the next wave of in-person examinations scheduled for 2016, which will allow for a more objective testing of these associations in the future.

The main strengths of the present results are derived from the large-scale nature of the ELSA-Brasil study, conducted in middle-income country on a cohort with a broad age spectrum in the context of a scientific production scenario that has accumulated abundant evidence through the study of adolescents and young or older people. As this study sample consists of a labour cohort, several aspects presented here can be further investigated through the analysis of longitudinal data and the incorporation of new variables that can add complexity to enrich the explanation of the phenomena under examination.

The authors hope that the results of our research will contribute to the prevention of chronic non-communicable diseases, as well as to help promote better health in Brazilian women and men, and also in other similar populations around the world. At the same time, these findings hold the potential to stimulate new studies to elucidate the complex mechanisms involved in the process surrounding healthy behaviours.

Acknowledgements The authors would like to thank all the researchers, staff and participants involved with the ELSA-Brasil study.

Contributors ALP conceived the paper, performed the statistical analysis, data interpretation and drafted the initial manuscript and the final paper. MdCA contributed to the data analysis, interpretation and writing of the final manuscript. SMAM and DC assisted with literature review, interpretation and aproved the final paper. EMLA contributed with intellectual content to the paper, analysed the data, assisted with literature review and wrote the final paper. All the authors approved of the final draft of the manuscript.

Funding The ELSA-Brasil baseline study was supported by the Brazilian Ministry of Health (Science and Technology Department) and the Brazilian Ministry of Science and Technology (Financiadora de Estudos e Projetos and the CNPq National Research Council) (grants 01060010.00 RS, 01060212.00 BA, 01060300.00 ES, 01060278.00 MG, 0106 0115.00SP, 01060071.00 RJ). The main author of this study received support from the Coordination for the Improvement of Higher Education Personnel (CAPES) programme through a research scholarship provided by 'Atração Jovens Talento', part of the Science without Borders initiative (reference: BJT A061/2013).

Competing interests None declared.

Provenance and peer review Not commissioned; externally peer reviewed.

Data sharing statement No additional data are available.

Open Access This is an Open Access article distributed in accordance with the Creative Commons Attribution Non Commercial (CC BY-NC 4.0) license, which permits others to distribute, remix, adapt, build upon this work non-commercially, and license their derivative works on different terms, provided the original work is properly cited and the use is non-commercial. See: http://creativecommons.org/ licenses/by-nc/4.0/

(c) Article author(s) (or their employer(s) unless otherwise stated in the text of the article) 2017. All rights reserved. No commercial use is permitted unless otherwise expressly granted.

\section{REFERENCES}

1. Bennet P, Murphy S. Psicologia e Promoção Da Saúde (Psychology and Health Promotion). Lisbon: Climepsi, 1999.

2. Duncan BB, Chor D, Aquino EML, et al. Chronic non-communicable diseases in Brazil: priorities for disease management and research. Rev Saúde Pública 2012;46:1:126-34.

3. Hamburg DA, Elliott GR, Health PDL. Behavior: frontiers of research in the Biobehavioral Sciences. Washington DC: National Academy Press, 1982.

4. Melonashi E, Shkembi F. A Predictive Model for Physical activity, Healthy Eating, Alcohol Drinking, and Risky Driving among Albanian Youth. Sage Open 2015;5:1-8.

5. Ogden J. Psicologia da Saúde (Health psychology). Lisbon: Climepsi, 2004.

6. Södergren M, Wang WC, Salmon J, et al. Predicting healthy lifestyle patterns among retirement age older adults in the WELL study: a latent class analysis of sex differences. Maturitas 2014;77:41-6.

7. Vrdoljak D, Marković BB, Puljak L, et al. Lifestyle intervention in general practice for physical activity, smoking, alcohol consumption and diet in elderly: a randomized controlled trial. Arch Gerontol Geriatr 2014;58:160-9.

8. Pearce N, Ebrahim S, McKee M, et al. Global prevention and control of NCDs: limitations of the standard approach. J Public Health Policy 2015;36:408-25.

9. Bennet P. Introdução Clínica à Psicologia Da Saúde (Clinical introduction for health psychology). Lisbon: Climepsi, 2002.

10. Routledge New York:. Blaxter M. Health \& Lifestiles, 1990.

11. Hankonem N. Psychosocial Processes of Health Behaviour Change in a Lifestyle intervention - Influences of Gender, Socioeconomic Status and Personality. Helsinki: National Institute for Health and Welfare, 2011.

12. Hansen E, Easthope G. Medicine Lifestyle in. Routledge New York: 2007.

13. Midanik LT, Soghikian K, Ransom LJ, et al. The effect of retirement on mental health and health behaviors: the kaiser permanent retirement study. J Gerontol B Psychol Sci Soc Sci 1995;50:1:59-61.

14. Zantinge EM, Berg M, Smit HA, et al. Retirement and a healthy lifestyle: opportunity or pitfall? A narrative review of the literature. European Journal of Public Health 2013;24:3:433-9.

15. Cutler DM, Lleras-Muney A. Understanding differences in health behaviors by education. J Health Econ 2010;29:1-28.

16. Hsu W, Chiang C, Yang S. The effect of individual factors on health behaviors among college students: the mediating effects of eHealth literacy. J Med Internet Res 2014;16:e287.

17. Paulik E, Boka F, Kertesz A, et al. Determinants of health-promoting lifestyle behavior in the rural areas of Hungary. Health Promotion International 2010;25:3:277-88.

18. Deeks A, Lombard C, Michelmore J, et al. The effects of gender and age on health related behaviors. BMC Public Health 2009;9:1-8.

19. Wagstaff A. Poverty and health sector inequalities. Bulletin of the World Health Organization 2002;80:2:97-105.

20. North Carolina Institute of Medicine. Prevention for the health of North Carolina: prevention Action Plan. Morrisville: North Carolina Institute of Medicine, 2010.

21. Pampel FC, Krueger PM, Denney JT. Socioeconomic disparities in health behaviors. Annu Rev Sociol 2010;36:349-70.

22. Ahnquist J, Wamala SP, Lindstrom M. Social determinants of health--a question of social or economic capital? Interaction effects of socioeconomic factors on health outcomes. Soc Sci Med 2012;74:930-9. 
23. Harvey IS, Alexander K. Perceived social support and preventive health behavioral outcomes among older women. J Cross Cult Gerontol 2012;27:275-90.

24. Bednarzyk MS, Wright TL, Bloom KC. Body image and healthy lifestyle behaviors of university students. International Journal of Advanced Nursing Studies 2013;2:107-14.

25. Wright TL. Body image and healthy lifestyle Behavior among University students. Jacksonville: University of North Florida, 2012.

26. Araujo J, Ramos E, Lopes C. Estilos De vida e percepção do estado de saúde em idosos portugueses de zonas rural e urbana [Lifestyles and self-rated health. in portuguese elderly from rural and urban areas] Acta Med Port 2011;24:79-88.

27. Hankivsky $O$. Women's health, men's health and gender and health: implications of intersectionality. Social Science \& Medicine 2012;74:11:1712-20.

28. Read Jen'nan Ghazal, Gorman BK. Gender and Health Inequality. Annu Rev Sociol 2010;36:371-86.

29. Jerdén L, Burell G, Stenlund H, et al. Gender differences and predictors of self-rated health development among Swedish adolescents. J Adolesc Health 2011;48:143-50.

30. von Bothmer MIK, Fridlund B. Gender differences in health habits and in motivation for a healthy lifestyle among swedish university students. Nursing and Health Sciences 2005;7:107-18.

31. Dean K. Self-care components of lifestyles: the importance of gender, attitudes and the social situation. Soc Sci Med 1989;29:137-52.

32. Sánchez-López MP, Cuellar-Flores I, Dresch V. The impact of gender roles on health. Women Health 2012;52:182-96.

33. Varì $R$, Scazzocchio $B, D^{\prime}$ Amore $A$, et al. Gender-related differences in lifestyle may affect health status. Annali dell'/stituto Superiore di Sanità 2016:52:158-66.

34. Griep RH, Toivanen S, van Diepen C, et al. Work-family conflict and self-rated health: the role of gender and educational level. Baseline data from the Brazilian Longitudinal Study of Adult Health (ELSA-Brasil). International Journal of Behavioral Medicine 2016;23:3:372-82.

35. Griep RH, Santos IS, et al. Work-family conflict, lack of time for personal care and leisure, and job strain in migraine: results of the Brazilian Longitudinal Study of adult Health (ELSA-Brasil). American Journal of Industrial Medicine 2016;4.

36. Pitanga FJ, Matos SM, Almeida MC, et al. Factors associated with leisure time physical activity among ELSA-Brasil participants: ecological model. Prev Med 2016;90:17-25.
37. Aquino EML, Barreto SM, Bensenor IM, et al. Brazilian longitudinal study of adult Health (ELSA-Brasil): Objectives and design. Am J Epidemiol 2012;175:315-24.

38. Camelo LV, Giatti L, Neves JA, et al. Life course socioeconomic position and $\mathrm{C}$-reactive protein: mediating role of healthrisk behaviors and metabolic alterations. The Brazilian Longitudinal Study of adult Health (ELSA-Brasil). PLoS One 2014;9:e108426-12.

39. Schmidt MI, Duncan BB, Mill JG, et al. Cohort profile: longitudinal study of adult health (ELSA-Brasil). InternationalJournal of Epidemiology 2014;0:1-8.

40. Chor D, Alves MGM, Giatti L, et al. Questionnaire development in ELSA-Brasil: challenges of a multidimensional instrument. Rev Saúde Pública 2013;47:2:1-9.

41. Duncan BB, Schmidt M I, Giugliani ERJ. Medicina Ambulatorial: condutas de Atenção Primária Baseada em Evidências (outpatient medicine: evidence-based primary care). Artmed Editora: Porto Alegre, 2004

42. Haskell WL, Lee IM, Pate RR, et al. Physical activity and public health: updated recommendation for adults from the American College of Sports Medicine and the American Heart Association. Med Sci Sports Exerc 2007;39:1423-34.

43. Geiser C. Data analysis with mplus. New York: Guilford Press, 2013.

44. Griep RH, Aquino EML, Chor D, et al. Test-retest reliability of the scale silhouettes figures of body image in Brazilian Longitudinal Study of adult Health. Cad Saúde Pública 2012;28:1790-4.

45. Green CA, Polen MR, Perrin NA. Structural models of gender, alcoho consumption, and health. Substance Use Misuse 2003;38:97-125.

46. Cea CJ, Santos RV. Health, minorities and inequality: some webs of inter-relations, emphasizing indigenous peoples in Brazil. Ciência \& Saúde Coletiva 2000;5:125-32.

47. Szwarcwald CL, Nogueira Damacena GN, Júnior $P$, et al. Determinants of self-rated health and the influence of healthy behaviors: results from the National Health Survey. Revista Brasileira de Epidemiologia 2013;18:33-44.

48. Neumark-Sztainer D, Paxton SJ, Hannan PJ, et al. Does body satisfaction matter? Five-year longitudinal associations between body satisfaction and health behaviors in adolescent females and males. J Adolesc Health 2006;39:244-51.

49. Grogan S. Body image: understanding Body Dissatisfaction in Men Women and Children. New York: Routledge, 2008. 